\title{
Effect of Frequency of Differential Capacities at Various Anodes in Aqueous Acetate or Propionate Solutions
}

\author{
Isao SEKINE*
}

\begin{abstract}
The interfacial differential capacities at platinum, gold, palladium, lead dioxide, and graphite anodes were measured with an a.c. bridge at different frequencies in aqueous solutions of acetate or propionate. The measured capacity varied almost linearly with the reciprocal of the square root of frequency $\left(f^{-1 / 2}\right)$, and at the same time, decreased with the increase of frequency for all the tested anodes in both carboxylate solutions. The resistance also decreased linearly with the increased frequency. The rate constants $\left(k_{\mathrm{s}}{ }^{\prime} \mathrm{s}\right)$ of the charge-transfer process of the anodic reaction were calculated from the capacitance data. The value of $k_{\mathrm{s}}$ was smallest, $2.8 \times 10^{-7} \mathrm{~cm} / \mathrm{sec}$, at the platinum anode, the greatest value was $4.2 \times 10^{-2} \mathrm{~cm} / \mathrm{sec}$ at the palladium anode undergoing only the oxygen evolution reaction. It was found that $k_{\mathrm{s}}$ at the anodes tends to increase with increasing frequency and with decreasing carboxylate concentration.
\end{abstract}

\section{Introduction}

For the electrolytic' oxidation reaction of carboxylate solutions, only a few papers appear to have been reported so far on the basis of the determination of kinetic parameters. Conway et al. measured the exchange current density $\left(i_{0}\right)$ in formate solution ${ }^{1)}$. Their values of $i_{0}$ are fairly close to those obtained by the authors in glacial acetic acid ${ }^{2}$. The exchange current density found in glacial acetic acid is less than $1 \times 10^{-10} \mathrm{~A} / \mathrm{cm}^{2}$, which is small as compared with the value of $i_{0}$ of general reversible electrode processes. This implies that the electrode processes are irreversible in glacial acetic acid and formate solution.

In the present work, the frequency dependence of the differential capacity at the anode interface has been studied with various anode materials in aqueous acetate or propionate solution. From the results of the capacity, resistance and their frequency dependence, the rate constant of charge-transfer process of the elec-

* Department of Industrial Chemistry, Faculty of Science and Technology, Science University of Tokyo (Noda, Chiba) trolytic oxidation was calculated using a theoretical equation of the faradaic impedance. Then, the electrode processes in both carboxylate solutions were discussed on the basis of $k_{\mathrm{s}}$.

\section{Experimental}

Measurements of the capacity were carried out by an a.c. bridge similar to that reported in the previous paper ${ }^{3}$. The test anodes used were platinum, gold, palladium, lead dioxide, and graphite. The pretreatment of the surface of these anodes was the same as that described previously $y^{3)}$. The frequency was arbitrarily adjusted to $0.1,0.5,1,5$, or $10 \mathrm{KHz}$ by a TōaDempa oscillator model CR-200 J. The capacity, for example, on the platinum anode was measured to a precision of about $\pm 2 \%$ at $2.0 \mathrm{~V}$ with $10 \mathrm{KHz}$ in $5 \mathrm{M}$ acetate concentration. The test solutions were prepared by mixing aqueous solution of acetate ${ }^{* 1}(0.5,1,2,5 M)$ or propionate ${ }^{* 2}(0.5,1,2 M)$ and $0.5 M$ pota-

*1 Aqueous: solution of the equimolar mixture of acetic acid and potassium acetate.

*2 Aqueous solution of the equimolar mixture of propionic acid and potassium propionate. 
ssium sulfate supporting electrolyte. All the measurements were carried out at $25^{\circ} \mathrm{C}$.

\section{Results and Discussion}

\section{1 Relationship between capacity and frequency}

According to the theory of faradaic impedance, the double layer capacity at the anodeelectrolyte interface can be obtained from the measured impedance at high frequencies. However, it is usually necessary to plot the capacity against the reciprocal of the square root of frequency, and to extrapolate it to an infinite frequency.

The relationship between the capacity and $f^{-1 / 2}$ value at $1.3 \mathrm{~V}$ and $2.0 \mathrm{~V}$ for various anodes in $5 \mathrm{M}$ aqueous potassium acetate solution is shown in Fig. 1. In the case of the platinum anode in aqueous acetate solution, the oxygen evolution was found to begin to

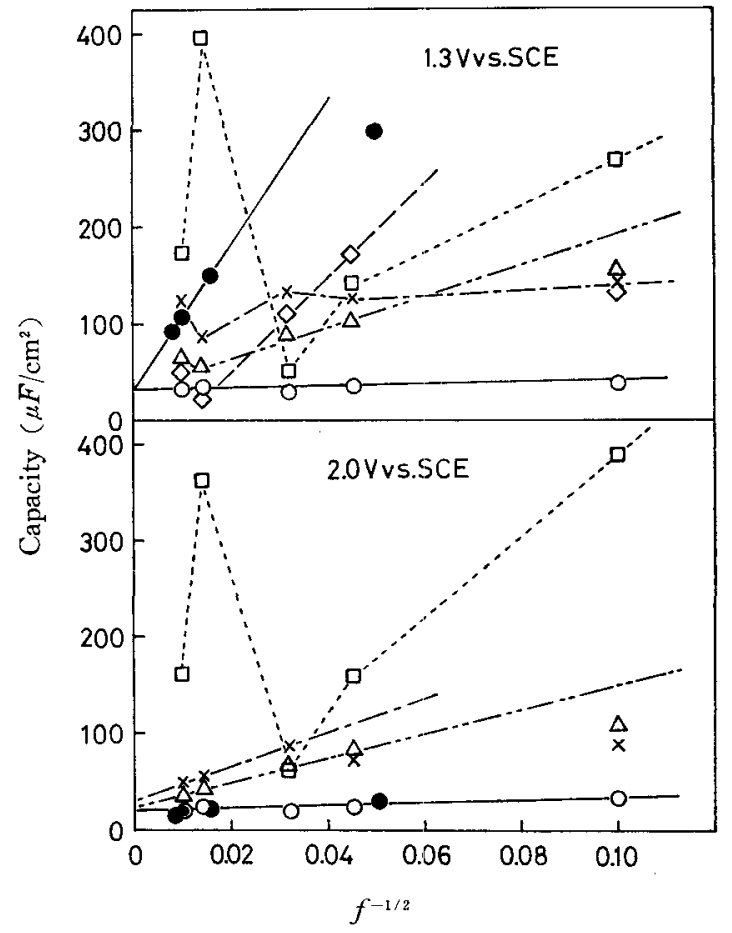

Fig. 1 Relationship between capacity and frequency at various anodes in $5 M$ aqueous acetate solution

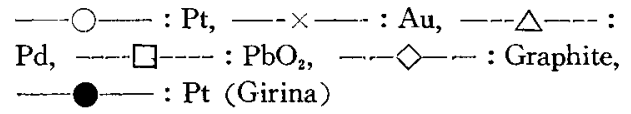

occur at around $1.3 \mathrm{~V}$, and the Kolbe reaction took place simultaneously at $2.0 \mathrm{~V}$, giving the Kolbe products. However, with other anodes, or in the aqueous propionate solution, the same did not occur at the same potential as that observed at the platinum anode in the acetate solution. Potentials of $1.3 \mathrm{~V}$ and $2.0 \mathrm{~V}$ in Fig. 1 were chosen as the reference potentials for the comparison of the anode materials. Except the case of lead dioxide the measured capacities at both potentials increased almost linearly with $f^{-1 / 2}$. The capacity value and its dependence on $f^{-1 / 2}$ at the platinum anode shown in Fig. 1 were the smallest of all the anodes within the frequency range employed. Although the linearity of the capacity $v s . f^{-1 / 2}$ relation was not good enough for anodes other than platinum to obtain the exact value from the extrapolation to an infinite frequency, we tried to obtain the value at infinite frequency. The obtained values were: $32 \mu F / \mathrm{cm}^{2}$ at $1.3 \mathrm{~V}$ and $21 \mu F / \mathrm{cm}^{2}$ at $2.0 \mathrm{~V}$ at the platinum, $25 \mu \mathrm{F} / \mathrm{cm}^{2}$ at $2.0 \mathrm{~V}$ at the palladium, and $31 \mu F / \mathrm{cm}^{2}$ at $2.0 \mathrm{~V}$ at the gold electrodes, respectively.

In the case of a lead dioxide electrode, the capacities at both $1.3 \mathrm{~V}$ and $2.0 \mathrm{~V}$ show maxima at $5 \mathrm{KHz}$. At present it is not clear why the maxima appear. Also, the capacity at $1.3 \mathrm{~V}$ at the high frequency of $10 \mathrm{KHz}$ on a graphite was found to be $46 \mu F / \mathrm{cm}^{2}$, which is close to $32 \mu F / \mathrm{cm}^{2}$ at the platinum. As a comparison, the data obtained by Girina ${ }^{4), 5}$ at the platinum anode in acetate solution are also plotted in Fig. 1 as filled circles. These values are extrapolated to an infinite frequency at $1.3 \mathrm{~V}$ to obtain $32 \mu F / \mathrm{cm}^{2}$ which agrees well with those obtained by the authors. The fact that the capacity lowers linearly with increasing frequency has also suggested by Sarmousakis and Prager $^{6)}$ at platinum in $1 N$ aqueous solutions of $\mathrm{KCl}, \mathrm{KBr}$, and $\mathrm{KI}$, respectively.

Fig. 2 shows the relationship between the capacity and $f^{-1 / 2}$ value at various anodes at $1.3 \mathrm{~V}$ in $2 M$ aqueous potassium propionate solution. In this figure, it is clearly seen that the capacity value at any given anode decreases almost linearly with increasing frequency, which is similar to that obtained in acetate solutions. Especially, the capacity on the gold 


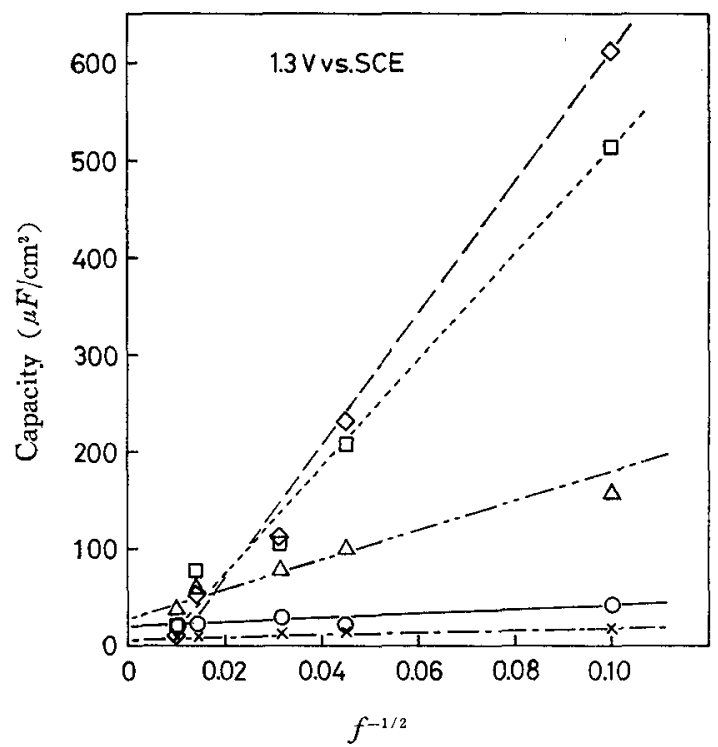

Fig. 2 Relationship between capacity and frequency at various anodes in $2 M$ aqueous propionate solution

$\longrightarrow \mathrm{Pd}: \mathrm{Pt}, \quad \mathrm{O} \times \mathrm{Pb} \longrightarrow \mathrm{Au},-\cdots \triangle---\mathrm{-}:$

is shown to be the lowest value in the whole frequency range employed. The capacity values extrapolated to an infinite frequency are $8 \mu F /$ $\mathrm{cm}^{2}$ on the gold, $23 \mu \mathrm{F} / \mathrm{cm}^{2}$ on the platinum, and $32 \mu \mathrm{F} / \mathrm{cm}^{2}$ on the palladium electrodes, respectively. However, extrapolation can not be made for lead dioxide and graphite, because of the fairely steep slope of the line in Fig. 2.

Because of the above mentioned difficulties for obtaining the capacity value at infinite frequency, a conventional value was obtained by extrapolating the plots to $10 \mathrm{KHz}$, the values for various anodes being summarized in Table 1 .
The capacity values $126 \mu F / \mathrm{cm}^{2}$ for gold and 172 $\mu F / \mathrm{cm}^{2}$ for lead dioxide in acetate solutions were fairly large, but the other anodes showed the values of about $50 \mu \mathrm{F} / \mathrm{cm}^{2}$. These values are in good agreement with those obtained from the capacity current density curves by the authors ${ }^{\text {?) }}$ who, employing a galvanostatic single pulse method at $10 \mathrm{~mA} / \mathrm{cm}^{2}$ in $5 \mathrm{M}$ acetate solution, obtained the capacity values as high as $144 \mu F / \mathrm{cm}^{2}$ at gold and lead dioxide, $67 \mu F / \mathrm{cm}^{2}$ at platinum, $58 \mu F / \mathrm{cm}^{2}$ at palladium, and $50 \mu \mathrm{F} / \mathrm{cm}^{2}$ at graphite.

The value obtained here appears to be reliable, since two different methods gave nearly the same value. Besides, in propionate solution the capacity at $2.0 \mathrm{~V}$ is lower than the one at $1.3 \mathrm{~V}$, and the capacity in propionate solution is also lower than the one in acetate solution. This result is in agreementw ith the results given in the previous paper ${ }^{82}$, in which a single pulse method was employed. Such differences in the capacity between the two solutions may be related to the fact that the reaction of formation of olefin (ethylene) occurs in propionate solution and it does not occur in acetate solution. The results in the present investigation by an impedance method consequently seems to support the explanation given in the previous paper ${ }^{8}$.

\section{2 Relationship between resistance and frequency}

Fig. 3 shows an example of plots of resistance $(R)$ against frequency at platinum in acetate solution. The log resistance decreases almost linearly with increasing log frequency. Such a tendency in resistance was also found at the other anodes, or in aqueous propionate solution.

Table 1 Differential capacities in $10 \mathrm{KHz}$ of various anodes $\left(\mu \mathrm{F} / \mathrm{cm}^{2}\right)$

\begin{tabular}{|c|c|c|c|c|c|c|c|c|}
\hline \multirow{3}{*}{ Anode } & \multicolumn{4}{|c|}{ Acetate } & \multicolumn{4}{|c|}{ Propionate } \\
\hline & \multicolumn{2}{|c|}{$1.3 \mathrm{~V}$ vs. S.C.E. } & \multicolumn{2}{|c|}{$2.0 \mathrm{~V} v s$. S.C.E. } & \multicolumn{2}{|c|}{$1.3 \mathrm{~V} v s$. S.C.E. } & \multicolumn{2}{|c|}{$2.0 \mathrm{~V}$ vs. S.C.E. } \\
\hline & $0.5 M$ & $5 M$ & $0.5 M$ & $5 M$ & $0.5 M$ & $2 M$ & $0.5 M$ & $2 M$ \\
\hline $\mathrm{Pt}$ & 35 & 32 & 48 & 23 & 32 & 25 & 12 & 7 \\
\hline $\mathrm{Au}$ & 45 & 126 & 45 & 48 & 17 & 10 & 12 & 6 \\
\hline $\mathrm{Pd}$ & 45 & 64 & 70 & 38 & 45 & 35 & - & - \\
\hline $\mathrm{PbO}_{2}$ & 128 & 172 & 104 & 160 & 10 & 20 & 10 & 25 \\
\hline Graphite & 41 & 46 & - & - & 20 & 10 & -- & 15 \\
\hline
\end{tabular}




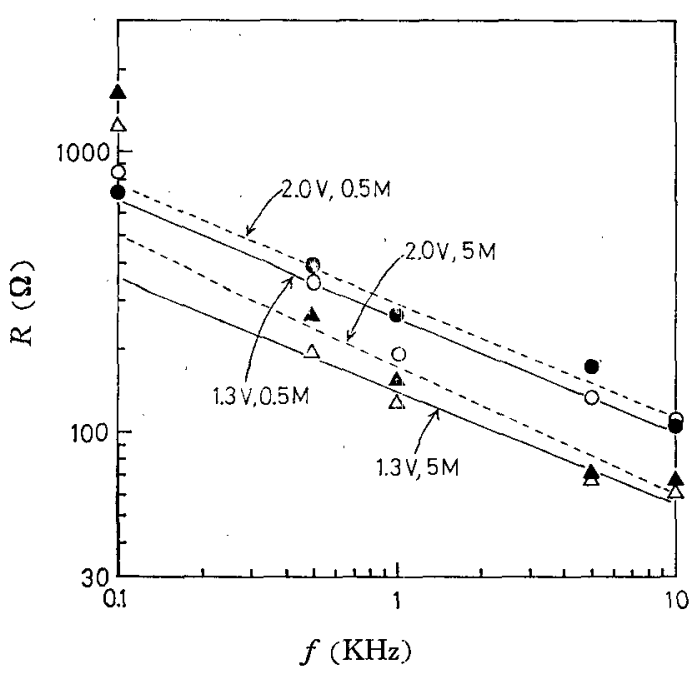

Fig. 3 Relationship between resistance and frequency at a platinum anode in aqueous acetate solution

The results of the resistance values at various anodes in both acetate and propionate aqueous solutions are listed for comparison in Table 2. As is evident from this table, the resistance is generally greater in propionate than in acetate solution. In addition, as for the variation of the resistance with carboxylate concentration, the resistance in acetate solution is lowered with increasing concentration, but in propionate solution the reverse is found. Such a tendency in resistance was recognized at each anode used. For example, the resistance at $2.0 \mathrm{~V}$ at $10 \mathrm{KHz}$ on the platinum anode in $0.5 \mathrm{M}$ acetate solution is $105 \Omega$, but it is small as $65 \Omega$ in $5 M$. On the other hand, in $0.5 \mathrm{M}$ propionate solution the resistance is $240 \Omega$, but it becomes greater as $265 \Omega$ in $2 M$.
These results might be velated to the dissociation constant of fatty acids, which issmall er for propionic acid $\left(1.4 \times 10^{-5}\right)$ than acetic acid $\left(1.86 \times 10^{-5}\right)$.

\section{3 Rate constant}

From the above data of the dependences of capacity and resistance on frequency, the rate constant as a kinetic parameter of chargetransfer process was calculated by the theoretical equation of the faradaic impedance ${ }^{9,10)}$. These values are summarized in Table 3 . The $k_{\mathrm{s}}$ values are seen to increase with decreasing carboxylate concentration and also with increasing frequency.

In general, it is probable to analyze the mechanism of the electrode reaction using the character of the faradaic impedance, especially for the case of the highly reversible process. In the electrolytic oxidation reaction of carboxylate solutions, the authors have already reported the irreversibility in the adsorption and desorption processes of hydroxyl ions or carboxyl ions on the anode-solution interface ${ }^{12), 137}$, the irreversibility being located in the discharge reaction of these ions and the values of $i_{0}$ being determined in glacial acetic acid $^{22}$. Taking these facts into consideration, it is presumed that the $k_{\mathrm{s}}$ values is too small.

The $k_{s}$ value in the present investigation was $2.8 \times 10^{-7} \mathrm{~cm} / \mathrm{sec}$ at $2.0 \mathrm{~V}, 0.1 \mathrm{KHz}$ on a platinum anode in $5 M$ acetate, which is the smallest, and the value was $4.2 \times 10^{-2} \mathrm{~cm} / \mathrm{sec}$ at $1.3 \mathrm{~V}, 5 \mathrm{KHz}$ on a palladium anode in $2 \mathrm{M}$ propionate solution, which is the largest.

These $k_{\mathrm{s}}$ values are close to the $i_{0}$ values obtained in glacial acetic acid containing $2 \%$ water, as reported in the previous paper ${ }^{2}$. The $i_{0}$ value was $1.5 \times 10^{-13} \mathrm{~A} / \mathrm{cm}^{2}$ at platinum,

Table 2 Resistances at various anodes $(\Omega)$

\begin{tabular}{l|r|r|r|r|r|r|r|r}
\hline \hline \multirow{3}{*}{ Anode } & \multicolumn{4}{|c}{$5 M$ acetate } & \multicolumn{4}{|c}{$2 M$ propionate } \\
\cline { 2 - 9 } & \multicolumn{2}{|c|}{$1.3 \mathrm{~V} v s$. S.C.E. } & $2.0 \mathrm{~V}$ vs. S.C.E. & \multicolumn{2}{c}{$1.3 \mathrm{~V}$ vs. S.C.E. } & $2.0 \mathrm{~V}$ vs. S.C.E. \\
\cline { 2 - 9 } & $0.1 \mathrm{KHz}$ & $10 \mathrm{KHz}$ & $0.1 \mathrm{KHz}$ & $10 \mathrm{KHz}$ & $0.1 \mathrm{KHz}$ & $10 \mathrm{KHz}$ & $0.1 \mathrm{KHz}$ & $10 \mathrm{KHz}$ \\
\hline $\mathrm{Pt}$ & 1210 & 59 & 1620 & 65 & 1583 & 95 & 1027 & 265 \\
$\mathrm{Au}$ & 203 & 58 & 432 & 155 & 4860 & 120 & 975 & 90 \\
$\mathrm{Pd}$ & 994 & 50 & - & - & 975 & 90 & - & - \\
$\mathrm{PbO}_{2}$ & 1625 & 317 & - & - & 588 & 441 & - & - \\
Graphite & 139 & 64 & - & - & 234 & 144 & - & - \\
\hline
\end{tabular}


Table 3 Rate constants at various anodes $(\mathrm{cm} / \mathrm{sec})$

\begin{tabular}{|c|c|c|c|c|c|c|c|c|c|}
\hline \multirow{3}{*}{ Anode } & \multirow{3}{*}{$\begin{array}{c}f \\
\left(\mathrm{KHz}^{2}\right)\end{array}$} & \multicolumn{4}{|c|}{ Acetate } & \multicolumn{4}{|c|}{ Propionate } \\
\hline & & \multicolumn{2}{|c|}{$1.3 \mathrm{~V}$ vs. S.C.E. } & \multicolumn{2}{|c|}{$2.0 \mathrm{~V}$ vs. S.C.E. } & \multicolumn{2}{|c|}{$1.3 \mathrm{~V}$ vs. S.C.E. } & \multicolumn{2}{|c|}{$2.0 \mathrm{~V}$ vs. S.C.E. } \\
\hline & & $0.5 M$ & $5 M$ & $0.5 M$ & $5 M$ & $0.5 M$ & $\because 2 M$ & $0.5 M$ & $2 M$ \\
\hline \multirow{2}{*}{$\mathrm{Pt}$} & 0.1 . & $5.2 \times 10^{-6}$ & $4.9 \times 10^{-7}$ & $3.4 \times 10^{-5}$ & $2.8 \times 10^{-7}$ & $2.5 \times 10^{-6}$ & $2.3 \times 10^{-4}$ & $1.3 \times 10^{-4}$ & $2.7 \times 10^{-5}$ \\
\hline & 5 & $3.3 \times 10^{-4}$ & $2.8 \times 10^{-5}$ & $3.0 \times 10^{-4}$ & $9.2 \times 10^{-6}$ & $6.2 \times 10^{-5}$ & $7.5 \times 10^{-5}$ & $2.4 \times 10^{-4}$ & $1.8 \times 10^{-5}$ \\
\hline \multirow{2}{*}{$\mathrm{Au}$} & 0.1 & $1.3 \times 10^{-5}$ & $2.3 \times 10^{-6}$ & $2.0 \times 10^{-5}$ & $2.8 \times 10^{-6}$ & $2.1 \times 10^{-6}$ & $7.2 \times 10^{-6}$ & $3.4 \times 10^{-4}$ & - \\
\hline & 5 & $2.2 \times 10^{-4}$ & $1.9 \times 10^{-5}$ & $3.9 \times 10^{-4}$ & $7.0 \times 10^{-5}$ & $1.4 \times 10^{-5}$ & $1.7 \times 10^{-5}$ & $9.2 \times 10^{-4}$ & - \\
\hline \multirow{2}{*}{$\mathrm{Pd}$} & 0.1 & $1.3 \times 10^{-4}$ & $3.8 \times 10^{-6}$ & - & - & $1.7 \times 10^{-3}$ & $8.2 \times 10^{-4}$ & 一 & - \\
\hline & 5 & $4.7 \times 10^{-3}$ & $2.9 \times 10^{-5}$ & - & - & $2.1 \times 10^{-3}$ & $4.2 \times 10^{-2}$ & - & - \\
\hline \multirow{2}{*}{$\mathrm{PbO}_{2}$} & 0.1 & $4.1 \times 10^{-5}$ & $3.4 \times 10^{-6}$ & - & - & $3.1 \times 10^{-4}$ & $1.6 \times 10^{-4}$ & $1.2 \times 10^{-3}$ & - \\
\hline & 5 & $8.1 \times 10^{-5}$ & $1.9 \times 10^{-4}$ & - & - & $3.5 \times 10^{-4}$ & $1.0 \times 10^{-3}$ & $5.3 \times 10^{-4}$ & $2.0 \times 10^{-4}$ \\
\hline \multirow{2}{*}{ Graphite } & 0.1 & $2.4 \times 10^{-5}$ & $4.4 \times 10^{-6}$ & - & - & $2.5 \times 10^{-4}$ & $2.4 \times 10^{-4}$ & - & $7.1 \times 10^{-4}$ \\
\hline & 5 & $2.0 \times 10^{-4}$ & $6.1 \times 10^{-5}$ & - & - & $2.5 \times 10^{-4}$ & $4.5 \times 10^{-5}$ & $1.5 \times 10^{-4}$ & $3.8 \times 10^{-5}$ \\
\hline
\end{tabular}

which is relatively small, and $5.3 \times 10^{-8} \mathrm{~A} / \mathrm{cm}^{2}$ at palladium, which is relatively large, $4.7 \times$ $10^{-10}$ at gold, $1.0 \times 10^{-14}$ at lead dioxide, and $1.4 \times 10^{-11} \mathrm{~A} / \mathrm{cm}^{2}$ at graphite.

Consequently, these differences in $k_{\mathrm{s}}$ can be explained as follows: When the oxygen evolution due to the discharge of hydroxyl ion is the predominant reaction as is the case of palladium, the effect of carboxylate ion is scarcely discernible. Because of the oxygen evolution reaction proceeded, the $k_{\mathrm{s}}$ value will probably be increased.

However, the $k_{\mathrm{s}}$ value in the case of platinum evolving the Kolbe products will most likely be decreased for the reason that the adsorption and discharge reaction of carboxylate ion is fairly inhibited by hydroxide ion.

\section{Summary}

(1) The differential capacities of platinum, gold, palladium, lead dioxide, and graphite anodes in aqueous acetate and propionate solutions were varied almost linearly with $f^{-1 / 2}$, and decreased with increasing frequency.

(2) The resistance also decreased linearly with increasing frequency.

(3) The rate constant ranged from the smallest value $2.8 \times 10^{-7} \mathrm{~cm} / \mathrm{sec}$ at platinum when the Kolbe reaction occurs to the greatest value $4.2 \times 10^{-2} \mathrm{~cm} / \mathrm{sec}$ at palla- dium when only the oxygen evolution reaction takes place.

(4) It was found that the rate constants tend to increase with increasing frequency and with decreasing carboxylate concentration.

\section{Acknowledgments :}

The author wishes to thank Professor T. Sekine, Tokyo Institute Technology, for instructive suggestions during this work. Thanks are also due to Mr. K. Aoki, Mr. H. Tsuchiya, Mr. K. Kanaya and Mr. $O$. Kondo for their contribution in the experimental work.

$<$ E 394> (Received July 25, 1974)

\section{References :}

1) B.E. Conway, M. Dzieciuch, Canadian J. Chem. 41, 38 (1963)

2) I. Sekine, T. Sekine, This Journal 38, 283 (1970).

3) I. Sekine, ibid. 41, 376 (1973).

4) G.P. Girina, Summary of Candidate's Thesis, Moscow, 1964.

5) A.P. Tomilov, S.G. Mairanovskii, M.Ya. Fioshin, V.A. Smirnov, "The Electrochemistry of Organic Compounds", p. 373 (1972), Halsted Press, New York.

6) J.N. Sarmousakis, M.J. Prager, J. Electrochem. Soc. 104, 454 (1957).

7) I. Sekine, T. Sekine, This Journal 37, 131 (1969).

8) I. Sekine, ibid. 41, 339 (1973).

9) P. Delahay, "New Instrumental Methods in Electrochemistry", p. 146 (1954), Interscience, New York.

10) R. Tamamushi, “Denki Kagaku”, p. 283 (1967), Tokyo Kagaku Dojin.

11) R. Tamamushi, This Journal 27, 60 (1959).

12) I. Sekine, T. Sekine, ibid. 36, 286 (1968).

13) I. Sekine, T. Sekine, J. Electrochem. Soc. Japan 36, 201 (1968). 